\title{
PALMAR DERMATOGLYPHICS OF THE PATIENTS WITH KLINEFELTER'S SYNDROME $(47, \mathrm{XXY})$
}

\author{
Yosuke Komatz and Osamu Yoshida \\ Department of Urology, Faculty of Medicine, Kyoto University, Kyoto, Japan
}

\begin{abstract}
Summary The frequency of palmar patterns and triradii of the palm prints of sixty-five 47,XXY Klinefelter's syndrome patients was compared with that of normal male and female subjects. There was no significant variation in the frequency of palmar pattern elements between the Klinefelter's syndrome group and the controls, except for the axial triradius of the Klinefelter's group, which was more distally located.
\end{abstract}

\section{INTRODUCTION}

There have been several studies concerning palmar patterns in 47,XXY Klinefelter's syndrome. In the palmar patterns of this syndrome, no characteristic findings, such as the increased hypothenar patterns associated with an ulnar triradius seen in the XXYY type (Shiono et al., 1977), have been noted (Schaumann and Alter, 1976). On the other hand, the frequencies of several palmar pattern elements in the XXY type were reported to be different from those of normal male and female subjects (Holt, 1968; Cushman and Soltan, 1969; Penrose and Loesch, 1970). The purpose of this study is, therefore, to clarify these contradictory findings.

\section{MATERIALS AND METHODS}

The palm prints of sixty-five patients with 47,XXY Klinefelter's syndrome, on which some other dermatoglyphic traits were reported previously (Komatz and Yoshida, 1977), and 100 normal male and 100 normal female subjects were studied. Pattern elements on the palm prints were classified according to the method proposed by Penrose and Loesch (1970) to compare the frequencies of loops and triradii in the patients and the controls. The palmar pattern intensity was expressed as the mean number of loops per palm in each group (Penrose and Loesch, 1970).

\section{RESULTS}

The occurence of loops was examined in the hypothenar area for $\mathrm{H}, \hat{\mathrm{H}}$ and $\mathrm{H}^{\mathrm{r}}$, in the area $I$ for $I$ and $I^{\mathrm{r}}$ and in the interdigital areas for II, III, III ${ }^{\mathrm{T}}, \mathrm{IV}$ and IV $^{\mathrm{T}}$ in 
both the patient and control groups. No significant differences were observed between them in the frequencies of these traits. However, radial loops $\mathrm{H}^{\mathrm{r}}$, which were not seen among the controls, were found in the hypothenar area of the right palm of two patients (Table 1).

Regarding triradii, the frequency of $t^{\prime}$ was significantly greater in the Klinefelter's syndrome group than in the male $\left(\chi^{2}=11.7\right.$, d.f. $\left.=1, \mathrm{P}<0.001\right)$ and female controls $\left(\chi^{2}=15.5\right.$, d.f. $\left.=1, P<0.001\right)$, if both palms were combined. No significant difference was noted among the three groups in the frequency of hypothenar triradii

Table 1. Frequencies and distribution of palmar patterns in Klinefelter's syndrome and control males and females.

\begin{tabular}{|c|c|c|c|c|c|c|c|c|c|c|c|c|}
\hline & \multicolumn{4}{|c|}{ Males $n=100$} & \multicolumn{4}{|c|}{ Females $\mathrm{n}=100$} & \multicolumn{4}{|c|}{$\begin{array}{l}\text { Klinefelter's } n=65 \\
\text { syndrome }\end{array}$} \\
\hline & $\mathrm{L}$ & $\mathrm{R}$ & $L+R$ & $\%$ & $\mathbf{L}$ & $\mathrm{R}$ & $L+R$ & $\%$ & L & $\mathrm{R}$ & $\mathbf{L}+\mathbf{R}$ & $\%$ \\
\hline I & 0 & 0 & 0 & 0.0 & 1 & 0 & 1 & 0.5 & 2 & 1 & 3 & 2.3 \\
\hline $\mathrm{Ir}$ & 13 & 2 & 15 & 7.5 & 5 & 2 & 7 & 3.5 & 4 & 1 & 5 & 3.8 \\
\hline II & 0 & 2 & 2 & 1.0 & 2 & 1 & 3 & 1.5 & 0 & 2 & 2 & 1.5 \\
\hline III, III'T & 22 & 41 & 63 & 31.5 & 17 & 33 & 50 & 25.0 & 10 & 22 & 32 & 24.6 \\
\hline IV, IVT & 82 & 66 & 148 & 74.0 & 83 & 66 & 149 & 75.5 & 56 & 39 & 95 & 73.1 \\
\hline $\mathrm{H}$ & 2 & 5 & 7 & 3.5 & 3 & 3 & 6 & 3.0 & 0 & 0 & 0 & 0.0 \\
\hline$\widehat{H}$ & 23 & 21 & 44 & 22.0 & 26 & 20 & 46 & 23.0 & 17 & 16 & 33 & 25.4 \\
\hline $\mathrm{H}^{r}$ & 0 & 0 & 0 & 0.0 & 0 & 0 & 0 & 0.0 & 0 & 2 & 2 & 1.5 \\
\hline Total & 142 & 137 & 279 & 139.5 & 137 & 125 & 262 & 131.0 & 89 & 83 & 172 & 132.3 \\
\hline
\end{tabular}

Table 2. Frequencies and distribution of palmar triradii in Klinefelter's syndrome and control males and females.

\begin{tabular}{|c|c|c|c|c|c|c|c|c|c|c|c|c|}
\hline & \multicolumn{4}{|c|}{ Males $n=100$} & \multicolumn{4}{|c|}{ Females $n=100$} & \multicolumn{4}{|c|}{$\begin{array}{l}\text { Klinefelter's } n=65 \\
\text { syndrome }\end{array}$} \\
\hline & $\mathrm{L}$ & $\mathrm{R}$ & $L+R$ & $\%$ & $\mathrm{~L}$ & $\mathrm{R}$ & $\mathrm{L}+\mathrm{R}$ & $\%$ & $\mathbf{L}$ & $\mathbf{R}$ & $L+R$ & $\%$ \\
\hline$e, f$ & 11 & 2 & 13 & 6.5 & 6 & 2 & 8 & 4.0 & 5 & 2 & 7 & 5.4 \\
\hline$t$ & 58 & 55 & 113 & 56.5 & 51 & 47 & 98 & 49.0 & 20 & 17 & 37 & 28.5 \\
\hline$t^{\prime}$ & 56 & 51 & 107 & 53.5 & 51 & 50 & 101 & 50.5 & 45 & 49 & 94 & 72.3 \\
\hline$t^{\prime \prime}$ & 0 & 0 & 0 & 0.0 & 0 & 1 & 1 & 0.5 & 0 & 0 & 0 & 0.0 \\
\hline$t^{\mathrm{b}}$ & 23 & 20 & 43 & 21.5 & 26 & 21 & 47 & 23.5 & 17 & 18 & 35 & 26.9 \\
\hline$t^{\mathrm{r}}$ & 0 & 0 & 0 & 0.0 & 0 & 0 & 0 & 0.0 & 0 & 0 & 0 & 0.0 \\
\hline$t \mathrm{u}$ & 1 & 1 & 2 & 1.0 & 0 & 0 & 0 & 0.0 & 0 & 0 & 0 & 0.0 \\
\hline$z$ & 0 & 0 & 0 & 0.0 & 0 & 0 & 0 & 0.0 & 0 & 0 & 0 & 0.0 \\
\hline$z^{\prime}$ & 11 & 2 & 13 & 6.5 & 10 & 6 & 16 & 8.0 & 8 & 6 & 14 & 10.8 \\
\hline$z^{\prime \prime}$ & 1 & 0 & 1 & 0.5 & 0 & 0 & 0 & 0.0 & 0 & 1 & 1 & 0.8 \\
\hline Total & 161 & 131 & 292 & 145.0 & 144 & 127 & 271 & 135.5 & 95 & 93 & 188 & 144.6 \\
\hline
\end{tabular}

Table 3. Palmar pattern intensity in Klinefelter's syndrome and control males and females.

$\begin{array}{ll}\text { Klinefelter's syndrome } n=130 & 1.323 \pm 0.067 \\ \text { Male controls } n=200 & 1.395 \pm 0.045 \\ \text { Female controls } n=200 & 1.310 \pm 0.039\end{array}$


$t^{\mathrm{b}}, t^{\mathrm{u}}$, triradii lying in area $\mathrm{I} e, f$ and interdigital triradii $z^{\prime}$ and $z^{\prime \prime}$ (Table 2). The palmar pattern intensity represented by the number of loops per palm showed no significant difference between the patients and the control males and females (Table 3 ).

\section{DISCUSSION}

Cushman and Soltan (1969) stated that hypothenar patterns and accompanying triradii were more abundant in XXY than in normal males, whereas Penrose and Loesch (1970) reported that they tended to be less frequent in XXY patients than in normal male and female controls. In the present study, no particular tendency was observed in the patients with Klinefelter's syndrome. Holt (1968) and Cushman and Soltan (1969) reported that the frequency of the patterns in the thenar/first interdigital area (area I) was higher in the control than the patient group. Such findings could not be confirmed in the present materials. It was often reported that the axial triradius was located more proximally in the case of XXY than in normal males and females, but recently many reports pointed out that it is located rather distally (Komatz and Yoshida, 1976). The present result revealed also the distal dislocation of the axial triradius in the Klinefelter's syndrome. Higher frequencies of the interdigital triradii $z^{\prime}$ and $z^{\prime \prime}$ were reported in Klinefelter's syndrome as well as in other sex chromosomal aberrations (Penrose and Loesch, 1970). In the present study, however, no significant difference was found among patient and normal materials. Though it has been observed that the palmar pattern intensity generally decreases with the increase in number of sex chromosomes (Penrose and Loesch, 1970; Saldana-Garcia, 1973 and 1975), the present data failed to reveal a significant decrease in this trait in the XXY group. Thus, the dermatoglyphic deviation of the Klinefelter's syndrome from the normal males and females was less remarkable in our subjects.

\section{REFERENCES}

Cushman, C.J. and Soltan, H.C. 1969. Dermatoglyphics in Klinefelter's syndrome (47,XXY). Hum. Hered. 19: 641-653.

Holt, S.B. 1968. The genetics of dermal ridges. Charles C Thomas, Springfield, Illinois.

Komatz, Y. and Yoshida, O. 1976. Position of axial triradius in 51 cases of 47,XXY Klinefelter's syndrome. Jap. J. Human Genet. 21: 123-128.

Komatz, Y. and Yoshida, O. 1977. Terminations of palmar main lines and main-line indices in 47,XXY Klinefelter's syndrome. Jap. J. Human Genet. 22: 281-286.

Penrose, L.S. and Loesch, D. 1970. Topological classification of palmar dermatoglyphics. J. Ment. Defic. Res. 14: 111-128.

Saldana-Garcia, P. 1973. A dermatoglyphic study of sixty-four XYY males. Ann. Hum. Genet. London 37: 107-116.

Saldana-Garcia, P. 1975. Dermatoglyphic findings in 54 triple-X females and a review of some general principles applying to soles in sex chromosome aneuploidy. J.Med. Genet. 12: 185-192. 
Schaumann, B. and Alter, M. 1976. Dermatoglyphics in medical disorders. Springer-Verlag, New York.

Shiono, H., Kadowaki, J., Tanda, H., and Hikita, M. 1977. Dermatoglyphs of Klinefelter's syndrome. J. Med. Genet. 14: 187-189. 